\title{
Creating Jobs and Reducing Unemployment among Nigerian University Graduates through Entrepreneurship Education
}

\author{
Abari A. Olasunkanmi ${ }^{1}$, Mohammed M. Olayiwola Babatunde ${ }^{1}$, Olufemi J. Eyo ${ }^{2}$ \\ ${ }^{1}$ Lagos State University \\ ${ }^{2}$ Doregos Advanced College \\ Nigeria
}

\begin{abstract}
Unemployment as a global phenomenon is on the increase especially in Nigeria. The rate of youth unemployment in Nigeria is put at $54 \%$ of the population [21]. It is also pertinent to note that this problem cannot be totally eradicated or solved but can be drastically reduced to its barest minimum through continious education and the acquisition of entrepreneural skills. Education is said to be the gradual acquisition of knowlwedge which is integrative in nature. Education as an on-going process does not end with acquisition of knowledge. The knowledge, understanding, skills, attitudes and competencies acquired must be constantly updated and stimulated through practical experiences and experiments. The practicality of the acquired knowledge births creativity and enterprise skills in the individual. This experiencial knowledge gives the individual an added advantage for better understanding and improvement thereby promoting his self esteem, self-efficacy and self confidence. It is believed that the co- curricullar character developed in the process of experiencing and experimenting makes the graduate to be bold enough to further venture into more risk by establishing a business of his/her own. All these will culmunate into the employability of the youth either by being more employable or being self employed. Also, all these reduce the rate of unemployment.
\end{abstract}

\section{Introduction}

There is a growing realization that the availability of resources and favourable government policies cannot guarantee rapid economic development of a nation. It is the entrepreneurial skill of the people that can transform the economy [4]. Thus, the quantity and quality of entrepreneurs are both essential for a country's transformation agenda.

Education is seen as an instrument required by entrepreneurs/students to acquire the necessary competencies through acquisition of relevant training and development. Education is essentially an instrument par excellence for national stability and development. Education is a dynamic process that changes with the needs and aspirations of the society [11].

Education is the gradual process of acquiring knowledge or it is the knowledge acquired by learning and instruction which could be formal or informal. Education is said to be a process of updating the knowledge and skills of individuals for the purpose of making that individual useful to himself or herself and to the community [22]. Education seeks integrative view of learning and development that emphasizes the connections and relationships between thinking, feeling and actions, rather than separating cognitive dimensions of education from affective or moral dimensions.

Entrepreneurial education is a lifelong process, starting as early as the elementary school and progressing through all levels of education, including adult education. It is seen as a tool which equips an individual to be an entrepreneur [4]. It focuses on developing understanding and capacity for pursuit of entrepreneurial skills and attributes. It enhances all-round development of body; mind and spirit. Entrepreneurship education involves opportunity recognition, commitment of resources and creation of a business of value to deliver goods and services [11]. Entrepreneurial education births an open mind in an empty brain. Entrepreneurial education can be guaranteed through the model posited by Sethi [25] and are in three phases: Stimulatory Phase- This phase involves planned publicity for opportunities, motivation, training and help and guidance in selection of product or service. Support Phase- This provides help in registration of units, arrangement of finance as well as land, sheds, power, water, common facility centres among others. Help is also provided in marketing of products. Sustenance Phase- it is the help provided for modernization, diversification and additional finance. Entrepreneurship education is bound to provide graduates with competencies 
that enhance enterprising skills, competencies of being a manager and those of a business owner

During the acquisition of entrepreneurial education, the outside world is introduced to the students. Here students are exposed to varied subjects like mathematics, social sciences, economics, humanities, literature among others. This knowledge being acquired prepares them for their interaction with the outside world. It gives room for a mixture of academic knowledge with experiential knowledge.

Whatever academic work is being taught, adequate opportunities are given to practically experience it. It is worthy of note that the mind will never grow without experiencing and experimenting. This experiential knowledge helps the students to have better understanding of whatever has been taught thereby helping them gain recognition in the society [14].They are equipped with boldness to face whatever is ahead and this gives them a leverage to become creative in tackling issues.

\section{Employment Generation through Entrepreneurial Education}

The entrepreneur's contribution to the total economic and social achievement, therefore, calls for initiating possible strategies for building the needed capacities and proper management policies for effective co-ordination of resources towards inculcating the spirit of independence, enterprise, innovation and nationalism [30]. Entrepreneurial skill acquisition plays a significant role in the generation of employment opportunities. Entrepreneurship as a purposeful activity is indulged in initiating, promoting and maintaining economic activities for production and distribution of goods and commodities. Entrepreneurial education serves as a means to develop the mind which gives room for creativity. Every society/economy is powered not just by information or by knowledge, but by human creativity [11]. Emaikwu asserts that Creativity is the ability to create meaningful new forms [11].

Creativity requires diversity. It is observed that creativity thrives when the environment allows people of all lifestyles, cultures, and ethnicities to interact [5]. Any society that wishes to encourage economic creativity (employment) must also encourage diversity. Three interrelated types of creativity are identified: technological creativity or innovation, economic creativity or entrepreneurship, and artistic and cultural creativity [8]. These three types of creativity are mutually dependent. In order to generate entrepreneurship (evident in higher rates of new business formation), a country or society must create conditions that stimulate innovation, arts, and culture. The three types of creativity stimulate and reinforce one another.

Creativity is to understand a situation, take the challenge and explore the means to achieve the goals [8]. A developed mind through the instrument of entrepreneurial education will always search for the opportunities to show its knowledge and the educational facts learned. It forms the core of a growing global economy and it births new economic opportunities in terms of wealth creation, employment generation, exploitation and local capacity utilization of cultural resources and revenue generation in the country.

Reports released by the National Universities Commission (2004) confirm that only about $40 \%$ of our university graduates in Nigeria are able to get paid employment in the public sector within five years of graduation [11]. Entrepreneurship education offers students the opportunity of helping them to anticipate and respond to changes. Students learn that though a job may be successfully accomplished today by performing certain tasks, tomorrow an entirely new set of skills may be required and because businesses are always changing, workers need to find out ways of doing a given job [11].

\section{Creating an Entrepreneurial Mindset}

Entrepreneurship has been proven to be a key ingredient of economic progress needed in all areas of human activities, from business to arts [31]. Entrepreneurship does not relate only to skills and attitudes required for creating and marketing profitably new products and innovative services but also to the general mind-set accepted and appreciated by all members of successful societies.

Although entrepreneurship is partly a result of genetic features of the individual and the impact of social environment, an important part can still be enhanced, developed and articulated through education and training. Therefore, entrepreneurial education is highly important for the development of human capital, and it is only in societies and economies where this is understood that there are good prospects of improving their performance and consequently international competitiveness. It is now increasingly accepted that entrepreneurship 
and knowledge are two indispensable, mutually reinforcing facets of knowledge economy [31].

Governments committed to upgrading their economies' competitiveness by unlocking the entrepreneurial potential in their countries have to create conditions which will make entrepreneurship a basic social value, and a key competence. In many cases, this implies an important change of mind set recognizing the strategic, positive contribution of entrepreneurship for enhancing the value of human capital and improving the economic performance of a society.

The key instrument of this mindset change is entrepreneurial education and training. It has to be fully integrated into the system of education and training at all levels, starting from primary school, and become an appreciated constituent part of curricula in all domains, from business management and marketing, to engineering, natural and social sciences, to philosophy and arts. This can be successfully achieved only if it will be part of a wider reform of the education and training system, in order to respond to the requirements of preparing young generations for the future jobs and professions, and to imbibe the system of lifelong learning.

As post-secondary education is critically important; the national and regional authorities should contribute consistently to the success of the reform processes with a view to strengthening further adjustments of the education system capable of developing skills and attitudes required by the present and future labour markets. More flexibility in recognizing outcomes from formal and informal learning environment is needed. Therefore, entrepreneurial education should be based on the following elements: (i) Fostering those personal attitudes and skills which support entrepreneurial mindset and behaviour (creativity, risk propensity, self-confidence, independence);

(ii)Raising awareness of students about selfemployment and entrepreneurship as possible career options; ( iii) Using practice-based methods with students being involved in project work and activities outside classroom (interacting with business world or with local community); (iv) Providing basic business skills for self-employment or self-management, and knowledge on how to start and develop a commercial venture or social venture [31].

\section{The Present Educational System in Nigeria and Its Weakness}

Education is essentially an instrument of excellence for national stability and development. Education is a dynamic process that changes with the needs and aspirations of the society. For education to be functional there must be constant and careful evaluation and re-evaluation of the educational system. Emaikwu [11] affirms that evaluation is a systematic process of judging the worth, desirability, effectiveness, or adequacy of something according to definite criteria and purpose and it always answers the questions: (i) how good...? (ii) Are the objectives realizable? (iii) What factors are hindering or facilitating the achievement of the desired objectives? (iv) To what extent are the objectives being achieved? (v) Is the process appropriate as to lead to the desired objectives? It has been asserted that education operates on the fundamental understanding that it will lead to changes in people's attitudes, skills, competencies, beliefs, and perspectives [11]. There could be no meaningful development in any country where its educational system is bedeviled by crisis of confidence.

One of the major weaknesses of the Nigeria's education system is its failure to prepare graduates for self-employment and business entrepreneurship [11]. It encourages the graduates to follow the tradition of job seeking. The general notion is that a good job is a government job, and not a job in the private sector. In Nigeria, the economic environment has changed drastically so much so that the public sector is diminishing in job creation, and economic liberalization is taking place to the extent that public enterprises are being privatized thus making the private sector an engine of economic growth [6]. Higher education may have contributed immensely in raising the level of educated Nigerian youths but may have failed in giving them the necessary orientation for selfreliance in the absence of paid employment in the country on graduation [23]. With the army of unemployed graduates roaming the streets every day, one wonders how far tertiary institutions in Nigeria have contributed to the socioeconomic growth and development of the country.

As stated in the report of the Nigerian Bureau of Statistics [21], the number of entrants into the labour market increased drastically as a result of the establishment of more universities (15 new universities), polytechnics (9) and colleges of education(9) since 2006. As a result, the rate of entrants was on the increase from 2007 to 2009 but 
declined significantly from 2009 to 2010 . The rate increased again from 2010 to 2011 . Within a five year period $(2007$ - 2011), there has been an average of about 1.8 million new entrants into the active labour market per year. The culminating effect showed that the national unemployment rate increased to $23.9 \%$ in 2011 compared to $21.1 \%$ in 2010 and $19.7 \%$ in 2009 . The rate is higher in the rural areas $(25.6 \%)$ than in the urban areas
$(17.1 \%)$.The result of the survey shows that persons aged $0-14$ years constituted $39.6 \%$, those aged between 15- -64 (the economically active population), constituted $56.3 \%$, while those aged 65 years and above constituted $4.2 \%$.

Table 1 shows the trend of unemployment from 2006 to 2011.

Table 1. Annual socio-economic report

\begin{tabular}{|c|c|c|c|c|c|c|}
\hline $\begin{array}{c}\text { Nigeria } \\
\text { Population }\end{array}$ & $\mathbf{2 0 0 6}$ & $\mathbf{2 0 0 7}$ & $\mathbf{2 0 0 8}$ & $\mathbf{2 0 0 9}$ & $\mathbf{2 0 1 0}$ & $\mathbf{2 0 1 1}$ \\
\cline { 2 - 7 } & $140,431,790$ & $144,925,607$ & $149,563,227$ & $154,349,250$ & $159,288,426$ & $164,385,656$ \\
\hline $\begin{array}{c}\text { Economically } \\
\text { Active }\end{array}$ & $78,922,666$ & $81,448,191$ & $84,054,533$ & $86,744,278$ & $89,520,095$ & $92,384,738$ \\
\hline Labour Force & $57,455,701$ & $59,294,283$ & $61,191,700$ & $63,149,835$ & $65,170,629$ & $67,256,090$ \\
\hline Employed & $50,388,650$ & $51,763,909$ & $52,074,137$ & $50,709,317$ & $51,224,115$ & $51,181,884$ \\
\hline Unemployed & $7,067,051$ & $7,530,374$ & $9,117,563$ & $12,440,517$ & $13,946,515$ & $16,074,205$ \\
\hline $\begin{array}{c}\text { Newly } \\
\text { Unemployed }\end{array}$ & & 463,323 & $1,587,189$ & $3,322,954$ & $1,505,997$ & $2,127,691$ \\
\end{tabular}

Source: National Bureau of Statistics [21]

Youth unemployment rate has been staggeringly very high in the country in the last ten years compared to the national unemployment rates. There were decreases in some years, but on the average, the youth unemployment rate is consistently about three times higher than the national average [1]. In Table 2, comparison is made on the youth unemployment rates in Nigeria to some other developed countries. With the exception of Spain, Nigeria's youth unemployment rate was higher in absolute terms than all the other developed countries. The rise in rates in 2010 for many countries has been attributed to the global recession which increased aggregate unemployment rates. However, for these countries, since 2011 youth unemployment rates have stabilized or fallen back slightly, perhaps as a result of specific government policies to help young workers [16]; [29]. Compared to sub-Saharan countries, Nigerian youth unemployment rate is far higher than theirs. Equally, other sub-Saharan
African countries maintain a stability in rate while that of Nigeria, though higher than other subSaharan African countries, increased from 30.7 in 2001 to 35.2 in 2010.

The trend in youths' engagement in socioeconomic activities in developing countries like Nigerian has been a thing of concern with many of them being unemployed. The youth unemployment crisis is not new, what is new is the staggering proportional increase it has reached in the recent time [9], [15].

It is quite indubitable that Nigeria is metamorphosing in all ramifications and education is expected to take a centre stage. Every positive development goes with change and change is always a dynamic process. Unemployment and poverty have become serious threats to Nigeria's development. 
Table 2. Youth unemployment comparison across countries

\begin{tabular}{|l|l|l|l|}
\hline $\begin{array}{l}\text { Country/year } \\
\text { Youth }\end{array}$ & \multicolumn{2}{|c|}{ Unemployment } & $\begin{array}{l}\text { Rates } \\
\text { Change }\end{array}$ \\
\hline & 2007 & 2010 & $\begin{array}{l}2007- \\
2010\end{array}$ \\
\hline Belgium & 18.8 & 22.4 & 19 \\
\hline Denmark & 7.9 & 13.8 & 74 \\
\hline Germany & 11.7 & 9.7 & -17 \\
\hline Ireland & 9.0 & 27.5 & 205 \\
\hline Spain & 18.2 & 41.6 & 19 \\
\hline France & 18.9 & 22.5 & 19 \\
\hline Italy & 20.3 & 27.8 & 36.9 \\
\hline Netherlands & 5.9 & 8.7 & 47.4 \\
\hline Portugal & 16.6 & 22.3 & 34.3 \\
\hline Sweden & 18.8 & 22.5 & 19.6 \\
\hline United Kingdom & 14.4 & 19.1 & 32.6 \\
\hline United States & 10.5 & 18.4 & 75.2 \\
\hline Sub Sahara Africa & 12.8 & 12.8 & 0 \\
\hline Nigeria & 30.7 & 35.2 & 14.6 \\
\hline Source: & & & \\
\hline & & & \\
\hline
\end{tabular}

Source: ILO Global Employment Trends for Youths [16]

These social vices have bred social ills such as armed robbery, youth restiveness, prostitution, hostage taking, and human trafficking [6]. These emerging issues call for education that will reorientate the mindset of youths towards enterprises, job creation, and poverty alleviation. To meet the global challenges, the curriculum of tertiary institutions needs to be overhauled to take care of some inadequacies. Institutions of higher learning in Nigeria have concentrated more on theoretical and abstract instructional deliveries, focusing only on cognitive development and consequently turning out no entrepreneurial skilled graduates into labour markets [10]. Curriculum experts have attested that there is the need to change from the hangover effects of theoretical liberal academics education which focused only on cognitive development to the utter neglect of entrepreneurship education that has its focus on practical occupational skills for self-employment, self-reliance, and sustainable development [18]. It would only take innovative economic system built upon the entrepreneurship foundation to keep an edge in the new knowledge-based global market system in the 21 st century and beyond.

It is globally acclaimed that entrepreneurship education through creation of new venture is a major engine of economic growth or a panacea for the stagnating or declining economic activity [18]. Hence, there is the need for entrepreneurial education. This need is attributable to high unemployment and poverty that have resulted to increase in crimes and social vices in Nigeria. Entrepreneurship education is a curriculum innovation for the school system designed to be a deliberate novel, specific change which is thought to be efficacious in accomplishing the goals of a system.

This curriculum innovation is predicated on the increasing rate of youth unemployment and general lack of entrepreneurial culture in the country. Its adoption is aimed at producing 
graduates with the right mind-set for starting business of their own and in the same vein, motivating others to start-up businesses for economic reliance [23]. The introduction of entrepreneurship education in the curriculum of tertiary institution is looked upon as the most effective way to fast track the transition of growing graduate population from theoretical education to the world of work. The government is optimistic and desirous of developing a concept of entrepreneurship education at all levels of education in the country, and it is hoped that this step will greatly help to reduce youth unemployment and increase sources of employment generation.

\section{Skills to Be Acquired For Employment Generation}

The target of development in any economy is the society or the people. According to Eriba as cited in Emaikwu [11], national development is viewed in terms of the absolute structural transformation of the socio-economic, political, cultural, scientific and educational set up of a nation. It is highly advocated that development must not only be brought about but it must be sustained. Education for sustainable development enables people to develop the knowledge, values and skills to participate in decisions about the ways in which things should be done collectively, either locally or globally, that will invariably improve the quality of life now and in the future [23].

Entrepreneurship skills to be acquired as developed in the CareerEdge model of employability by the STEM- Fields (science, technology, engineering and mathematics) in Pool and Sewell [7] are broadly termed generic skills which are: imagination/creativity, adaptability/flexibility, willingness to learn, independent working / autonomy, working in a team, ability to manage others, ability to work under pressure, good oral communication, communication in writing for varied purposes/audiences, numeracy, attention to detail, time management, assumption of responsibility and for making decisions, planning, coordinating and organizing ability, ability to use new technologies and commercial awareness. The enterprise skills suggested by Rae [24] would also include: initiative, problem solving, identifying and working on opportunities, leadership, acting resourcefully and responding to challenges among others.

Enterprise skills are included within the Generic Skills element of the CareerEDGE model of Employability as depicted in Figure 1.

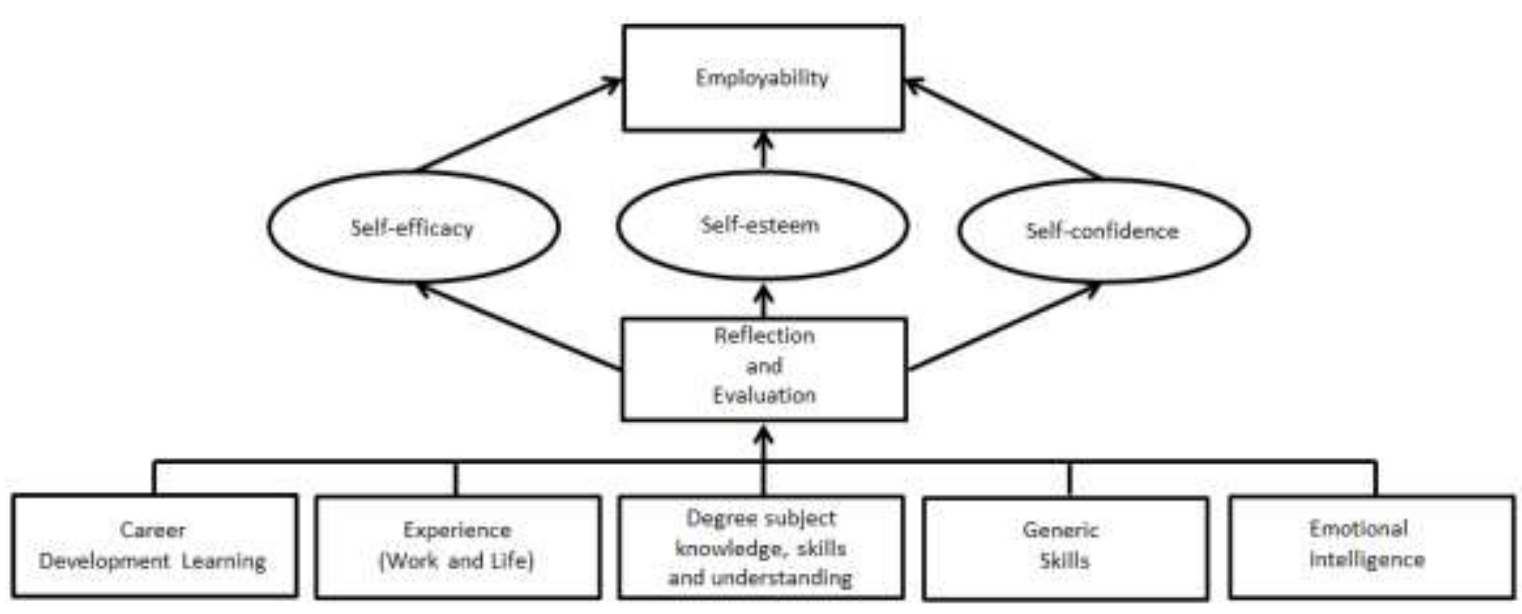

Figure 1. CareerEDGE - the essential components of graduate employability [7]

\section{The Need for Entrepreneurial Skill Acquisition}

Entrepreneurial development is a self-reliant approach to economic strength, recovery and a new technique to both business organizations as well as the public sector of the economy, development being seen in terms of reduction or elimination of poverty and inequality and unemployment within a growing economy like Nigeria [30]. 
Entrepreneurship as a whole contributes to social wealth by creating new markets, new industries, new technology, new institutional forms, new jobs and net increases in real productivity. The jobs created through their activities in turn lead to equitable distribution of income which culminates in higher standards of living for the populace. In this way, the resources available to the government will likewise increase and hence enable it to offer social services like hospitals and schools, develop the infrastructure and keep law and order.

The introduction of the entrepreneurship skill acquisition into educational system will enable the youths to become enterprising, innovative and creative. They will be job creators rather than job seekers in the economic system of any country [23]. The introduction of the entrepreneurship education in the educational system will naturally consolidate developed partnerships that will promote the possibility of harnessing diverse ideas, knowledge, expertise, experiences and skills for national development. The resultant effect will be effective and efficient resources management, sustained economic development as well as scientific and technological breakthrough [10].

The inculcation of entrepreneurship skills' acquisition in the university curriculum will also have implication on the youth transformation, reducing youth restiveness, robbery, political thuggery, unemployment, and so on. The problem of resource wastage, wastage of capital and corruption will be a thing of the past. The tendency of greed will be reduced, as this form of education will ensure transparency in financial management among entrepreneurs and subsequent transfer to the public life. Transparency will of course become a living principle which will consequently be a culture in the wider sector of the economy and national development will become an assured project [10]. Entrepreneurship skills' acquisition could lead to a viable economy with more employers rather than employees thereby having a cream of capable men and women who will positively influence the national economy and who could participate in the development process [11]. The national environment will become a business economy, rationalizing social inequalities in pursuant of the human-centered socio-economic development and reforms. With the right investment in entrepreneurship and the encouragement to succeed, young people will create their own jobs and, in many cases, hire others [19]. They can and will invent the next big things that change lives, lift up communities and grow economies.

The inculcation of entrepreneurship skills in the students of tertiary institutions will lead to the creation of awareness and understanding of the socio-economic and environmental situation for sustainable national development [19]. It will ensure stable national growth in the provision of employment options for Nigerian graduates. Entrepreneurship education could lead to capacity building of the beneficiaries mentally, physically and intellectually thereby placing them on the advantage of acquiring, interpreting, extrapolating information and consequently applying such capacities in building self in particular and the nation in general. Entrepreneurship skills' acquisition in the university education could provide the needed solution to the complex developmental problems of the nation such as resource wastage, hunger and disease control. It will lead to opportunities for individuals and collective development of latent potentialities for self fulfillment and actualization [23]. Moreover, the general avoidable ignorance and poverty will be reduced among graduates in as much as entrepreneurship skills' acquisition is embraced. The importance of entrepreneurship education lies in creation of jobs, stimulation of innovation, and provision of opportunities for Diverse People in the Country [14].

\section{Impediments to Entrepreneurship Education in Nigeria}

One of the major obstacles likely to impede the entrepreneurship education is that teachers lack motivation and specific training. The efforts that teachers devote to practice-based activities, sometimes even outside their normal working hours are not recognized as official tasks. Nigeria government has not thought it necessary to establish an entrepreneurship education centres to develop and coordinate entrepreneurship at different ministries, organizations, and educational institutions [11]. In the few areas where the centres are established, these centres are not adequately funded by relevant authorities. Sourcing of project capital has always been the bane of the new ventures in Nigeria. Private partnerships are crucial to the development of entrepreneurship education.

The establishment of school-business community link is a key element of successful programmes. This process is not encouraged in Nigeria thereby hindering the effective development of entrepreneurship education [23]. 
Private actors are becoming more involved in education by sponsoring specific initiatives and participating directly in teaching as mentors. This involvement is not seen by firms as a long term investment as well as an important aspect of their corporate social responsibility. Students pursuing higher education are not often encouraged to be involved in one profit yielding venture or the other as a way of preparing them for the world of work on graduation [10].

Entrepreneurship skill acquisition course is often housed in general studies department in many universities and taught by lecturers who do not possess any basic training in entrepreneurship education and hence lack the skills to impart the knowledge effectively. It is only trained teaching personnel that can understand and impart entrepreneurial subject matter in an inspiring manner to develop entrepreneurial minded students who will meet the nation's economic goals [18] Government tax policies on small businesses could discourage entrepreneurial industrial development. Government hardly creates enabling the environment under which entrepreneurship would flourish. The presence of legislative constraint often leads to imposition of multiple taxation and levies on small businesses.

\section{Conclusion}

Entrepreneurship can become a solution to unemployment in Africa but everyone taking that route must be fully equipped [29]. There is a huge need in different fields that can be filled by innovative young graduates: there is a huge need for social entrepreneurs; a huge need for agriculture based businesses and a huge need for technology related businesses just to name a few. If graduates decide to seek jobs but to no avail, they can just look for a need in their community that they can fill and make a business out of it. If done right with the necessary support, being self employed is more rewarding than working for someone. Instead of blaming the government for unemployment, young people should be encouraged go out there and find solutions for themselves and their peers through entrepreneurial education [6].

What will be seen happening will be a group of young people who are operating successful businesses and creating employment and this may reduce the rate of unemployment? Africa is mostly dependent on natural resources. If individuals are well equipped with entrepreneurial skills, young people can stay focused and do their best to build successful and sustainable businesses. This will end up contributing massively to the economy of their countries. It is evident that there are many brilliant young people in Africa especially in Nigeria with amazing ideas. What is needed is for them to be empowered; for them to be encouraged to take all those ideas and turn them into reality; for them to be encouraged to stop depending too much on the government and start fending for themselves. Unemployment is a serious problem but entrepreneurship is one solution that young people can consider [27].

It is increasingly being appreciated today that small businesses offer the best prospects for the expansion of employment opportunities in this country. This is because avenues for wage employment (job) in the formal sector are dwindling. It is important that local entrepreneurial potentials are developed; otherwise, there would be little prospects for solving the high unemployment rate problem confronting the nation Nigeria [27]. There is therefore the need to give orientation, information and requisite training and support to channel the creative and innovative ideas of young people into starting their own businesses in order to be employed and also be employers of labour.

\section{Recommendations}

One of the ways to ensure employability of graduates is to include, 'enterprise skills' as a fundamental component of academic provision at all levels. This clearly makes sense as a strong case can be made of the need for all students and graduates to have access to opportunities that will enhance their employability. It is also possible to identify methods by which such an objective can be achieved: for example, through work placements, student projects with employers and career development related activities. (This is already in practice in the polytechnics and for some courses in the universities). This is buttressed by Akudolu [2] that Entrepreneurship education as general education across all levels of education should be made a policy issue.

Entrepreneurship will be important to more students, and it is essential that for those students, appropriate opportunities and support is made available when they need it: for example, the provision of modules and workshops supporting entrepreneurial activity. It may be that because of the nature, some courses may feel it would be beneficial to embed opportunities for their students to engage with this type of skill development. But this will not apply to all courses and as such it 
would not be appropriate to recommend that entrepreneurship development activities be embedded in such courses [28].

It would be important for 'Teaching and Learning' strategies to recognize that some staff will be less experienced and knowledgeable about adopting such approaches to the delivery of their curriculum. Therefore appropriate training opportunities need to be available together with ongoing support in order to maximize the success of this approach [28]. Rae [24] agrees that in order to implement such a strategy effectively, university staff will need leadership, encouragement, inspiration and updating on current practices.

Therefore, practising teachers at all levels of education should undergo professional training through seminars, workshops and other in-service training to acquire knowledge and skills in the adoption of entrepreneurship - driven instructional methodology [20]. Dimensions of entrepreneurship should be a component of teacher preparation curricular. Federal and State Ministries of Education should build resource centres and networks for exchange of good educational practices. School administrators should establish linkages with entrepreneurs [27].

Another key response in promoting employability through entrepreneurship development is the adoption of some form of employability/enterprise/entrepreneurship award [26]. There are essentially two approaches to this response. The government can either identify modules, elements of programmes and /or cocurricular experiences with employability, 'enterprise skills' or entrepreneurship activities.

These can then be 'badged' as suitable for contributing towards the final award which is an integral part of the degree programme. Alternatively additional modules, workshops and co-curricular activities can be accredited in such a way that they contribute towards a separate additional award over and above the degree programme [26].

\section{References}

[1] Alabi, T. (2014). Youth Unemployment and Crime Control: an Analysis of Nigerian Experience. European Scientific Journal, January 2014 10(2)

[2] Akudolu, L.R. (2010). A Curriculum Framework for Entrepreneurship Education in Nigeria. Journal of Education, 5(2), July 2010.
[3] Akudolu, L.R. (2001). Curricular Issues In Entrepreneurship Education. Journal of Sciences and Computer Education.

[4] Antoncic, B. and Hisrich, R. D. (2003). Clarifying the Intrapreneurship Concept. Journal of Small Business and Enterprise Development, 10(1), Pp. 7 - 24.

[5] Charantimath Poornima,(2006). Entrepreneur Development Small Business Enterprise. Darling Kindersley (India) Pvt. Ltd., New Delhi.

[6] Charles Oliver (2013). Young Entrepreneurs Drive: Solution to Youth Unemployment Crisis, (Oct. 14)

[7] Dacre, P. L. \& Sewell, P (2007). The Key to Employability: Developing a Practical Model of Graduate Employability. Education \& Training, 49(4), Pp $277-289$.

[8] Edem Duke, (2013). Creativity Is A Panacea To Youth Unemployment. Sunday Trust Newspaper, 2013.

[9] Egunjobi T.A. (2007). Crime and Unemployment: an Empirical Analysis. A paper presented at Annual Conference of Nigerian Economic Society. August 2006.

[10] Ekong, A. O. (2008). Entrepreneurship education: A positive re-direction for Nigeria's National Development Journal Educational Innovators, 1(2), PP. 1-16.

[11] Emaikwu S.O., (2011). Integrating Entrepreneurship Skill Acquisition in the University Curriculum for National Development. A Journal of Research in Education and Society, Vol.2(3).

[12] Florida,R. (2002). Entrepreneurship, Creativity and Regional Development. Carmegie Mellon University.

[13] Gomelz-Mejia, L. R. and Balkin D. B. (2002) Management. Boston: McGraw-Hill/Irwin Ltd.

[14] Hisrich, P. (1995). Entrepreneurship: Starting, Developing \& Managing New Enterprise. Irwin, Chicago, Third Edition.

[15] ILO (2012), Global Employment Trends 2012: Preventing a deeper jobs crisis.

[16] ILO (2011). Enterprise-based Youth Employment Policies, Strategies and Programmes: Inititative for the development of enterprise and strategies, ILO Skills working paper No. 1.

[17] Lorraine D. P. (2012). The CareerEdge Model of Graduate Employability. Pedagogy of Employability Implications for Practice, 2012.

[18] Matlay, H. (2005). Entrepreneurship and learning: The double act in the triple helix. International Journal 
of Entrepreneurial Behavior and Research, 5 (2), PP. 4863

[19] Moreland, N., (2006). Entrepreneurship and Higher Education: An Employability Perspective. The Higher Education Academy: New York.

[20] Nabi, G. and Holden, R. (2008). Graduate Entrepreneurship: Intentions, Education and Training. Education and training 50(7), Pp $545-551$.

[21] National Bureau Of Statistics, (2011). Annual Socio-Economic Report.

[22] Okebukola, P.A.O., (2014). Education, Entrepreneurship and Employability. A Paper Presented At The $1^{\text {st }}$ International Of The Faculty Of Education, Lead City University, Ibadan In Partnership With Global Education Network.

[23] Osalor Peter, (2013). Entrepreneurial Education Revolution: An Imperative for Sustainability in Nigeria.

[24] Rae, D. (2007). Connecting Enterprise and Graduate Employability. Challenges To The Higher Education Culture And Curriculum? Education \& Training, 49, 8/9, Pp 605-619.

[25] Sethi, J. (2010). Entrepreneur and Entrepreneurship. (Www.Smallindustryindia.Com)

[26] Sewell And Dacre Pool, (2010). Moving From Conceptual Ambiguity To Operational Clarity: Employability, Enterprise And Entrepreneurship In Higher Education.

[27] The Nigerian Voice (2013). Challenges of Educational System.

[28] The Pedagogy for Employability Group (2006). Pedagogy for Employability. The Higher Education Academy: New York.

[29] Vremudia.P. Diejomaoh (2012): African Youth Empowerment Programmes: Guidelines for Accelerating Implementation. (UNDP/African Union Commission Addis Ababa (2012)

[30] Sackey, J.A., Ejoh, N.O. and Jude U. B. (2013). Entrepreneurship and employment generation: The formal and informal sector perspectives. Archives of Applied Science Research, 2013, 5 (5): PP 20-27. Retrieved from http://scholarsresearchlibrary.com/aasrvol5-iss5/AASR-2013-5-5-20-27.pdf (17/7/2016)
[31] University of Wolverhampton K.E.N. (2013) Entrepreneurial Education \& Innovation Developing Entrepreneurial Mindset for Knowledge Economy. Retrieved from http://www.knowledgeeconomy.net/ uploads/documents/2013/workshops/wolverhampton/Wo lverhampton Workshop (13/7/2016). 
International Journal of Innovative Business Strategies (IJIBS), Volume 2, Issue 1, June 2016 